\section{Recommendations for Stroke Networks in Primary Care}

\section{Henk J Arwert ${ }^{1,2,3 *}$, Jetty HR Borcherts ${ }^{1}$, Felicie M van Vree ${ }^{1}$, Iris F Groeneveld ${ }^{4}$, Jorit JL Meesters ${ }^{1,3}$, Thea PM Vliet Vlieland ${ }^{1,3}$ and Paulien H Goossens ${ }^{5}$}

${ }^{1}$ Basalt Rehabilitation Center, The Hague, Netherlands

${ }^{2}$ Haaglanden Medical Center, The Hague, Netherlands

${ }^{3}$ Leiden University Medical Center, Leiden, Netherlands

${ }^{4}$ Zorginstituut Nederland, Diemen, Netherlands

${ }^{5}$ Merem Rehabilitation Center, Hilversum, Netherlands

\section{Abstract \\ Background}

The longer term consequences of stroke may demand multidisciplinary therapy in primary care, but the requirements regarding skills and organization are unclear. The objectives of this qualitative study were to describe the structure and processes of primary care stroke networks in the Netherlands and to formulate recommendations for further development.

\section{Methods}

Fifteen networks met the pre-defined definition, varying from 4-140 members. Information on the structure and processes of the networks was systematically collected from their coordinators and members. An invitational conference with stakeholders was organized to discuss recommendations.

\section{Results}

Most members were physical therapists, 12 networks were multidisciplinary; 14 networks had membership entry criteria, 8 imposed a membership fee. Standardized treatment programs and/or measurements were used by 9 networks. 139 Network members from 15 networks completed the online survey. In the preceding year, $48 \%$ followed postgraduate education on stroke, $90 \%$ took part in network

*Corresponding author: Henk J Arwert, Basalt Rehabilitation Center, The Hague, Netherlands, Tel: +31 6 51409017; E-mail: h.arwert@basaltrevalidatie.n

Citation: Arwert HJ, Borcherts JHR, Vree FMv, Groeneveld IF, Meesters JJ, et al. (2019) Recommendations for Stroke Networks in Primary Care. J Phys Med Rehabil Disabil 5: 039.

Received: November 01, 2019; Accepted: December 03, 2019; Published: December 10, 2019

Copyright: ( 2019 Arwert HJ, et al. This is an open-access article distributed under the terms of the Creative Commons Attribution License, which permits unrestricted use, distribution, and reproduction in any medium, provided the original author and source are credited. meetings and $78 \%$ had seen $>5$ stroke patients. Time and money were most frequently mentioned as barriers for the development of the network. Mutual trust, commitment and direct communication lines were mentioned as success factors.

\section{Conclusion}

Large variation was observed in the structure and processes of 15 primary care stroke networks in the Netherlands. Recommendations for the organization and development of primary care stroke networks were formulated. A national approach towards their organization and development was advocated.

Keywords: Network; Process; Primary care; Stroke; Structure

\section{Introduction}

Every year around 45,000 people in the Netherlands suffer from a first cerebrovascular accident or stroke [1]. The prevalence of stroke patients in the community is 315,000 in the Netherlands $(2 \%$ of the population) [2]. In the United States of America, the death rate with respect to stroke is decreasing considerably, which leads to an increasing prevalence of stroke survivors; $56 \%$ of stroke patients were discharged to their homes after hospitalization in 2011 and $44 \%$ were discharged to inpatient rehabilitation or skilled nursing facilities of whom a majority returned to their homes [3]. The same pattern is observed in the Netherlands [4].

Recent literature shows that community dwelling stroke survivors do not always receive the optimal amount and type of care [5], which may lead to unmet needs and unnecessary restrictions in activities and participation [6-8]. These problems could be prevented by implementing well-organized networks of health professionals in primary care, with the common goal of improving the quality and continuity of care and enhancing communication between primary health care providers [9]. Stampa et al. described some practical guidelines to support the active participation of general practitioners in these networks, considering their central role as gatekeeper to healthcare [10].

A Cochrane review showed that the functional status in stroke patients seems to improve slightly by externally facilitated interprofessional activities, but the methodological quality of the studies varied largely [11]. In another study, patients and caregivers receiving follow-up were generally more satisfied with aspects of communication, and had a greater knowledge of stroke [12]. A randomized controlled trial in the UK concerning a new post-discharge system of care comprising a structured assessment covering longer-term problems experienced by patients with stroke and their carers, demonstrated no benefit in clinical or cost-effectiveness outcomes associated with the new system of care compared with usual practice [13].

Recently a review was carried out to construct hypotheses for the development of a primary care model which aims to provide sustainable long-term support for stroke survivors and informal carers in the community [14]. 51 studies (including 168 stroke survivors and 328 caregivers) were synthesized. It was concluded that stroke survivors 
and caregivers feel abandoned because they have become marginalized by services and they do not have the knowledge or skills to re-engage. This can be improved by: (1) increasing stroke specific health literacy by targeted and timely information provision, and (2) improving continuity of care between specialist and generalist services.

In the Netherlands, primary care networks have been established for several chronic conditions such as rheumatic and musculoskeletal conditions, Parkinson's disease or peripheral arterial disease resulting in increasing expertise, better communication and higher patient satisfaction [15-19]. Over the past years, Primary Care Stroke Networks (PCSN) have also been formed in several regions in the Netherlands. However, insight into their number and organizational features is lacking. The aim of this qualitative study is to obtain an overview of the primary care stroke networks PCSN in the Netherlands and describe their structure and processes. Moreover, an inventory of barriers and facilitators for their development is made, and recommendations for their optimal organization are formulated.

\section{Methods}

This study was carried out between June 2016 and September 2017. It concerned an online survey among network coordinators and members, and a subsequent invitational conference with relevant stakeholders. Because patient data were not involved the study fel outside the remit of the Medical Research Involving Human Subjects Act. All data of coordinators and members were processed anonymously.

The triad of structure, process, and outcome was used to evaluate the quality of PCNS [20]. In this concept "structure" is defined as the settings, qualifications of providers, and administrative systems through which care takes place; "process" as the components of care delivered; and "outcome" as recovery, restoration of function, and survival. These concepts are the foundation of quality assessment and are used to describe the characteristics of a PCN in a formal way [21].

\section{Identification of Existing Networks}

The following definition of a network was used: "Any collaboration of health care providers (either or not with the same professional background and not only comprising general practitioners and/or home care) in primary health care, with formal agreements about cooperation and / or the content of care provision to people with stroke". The network could be focused on other neurological patient groups in addition as well (e.g. brain injury) but their dedication to stroke had to be explicitly formulated.

Networks were identified and approached between June 2016 and September 2017, using various methods. First, information was obtained from the Knowledge Network for Stroke (www.CVAkennisnetwerk.nl), of the working group for stroke the Netherlands (WCN, part of Netherlands Society of Rehabilitation Medicine), the Dutch Society for neurology and the snowball method among all involved in the project. Second, a call inviting PCSN to participate in the project was made using various media relevant for healthcare providers involved in the treatment of people with stroke (e.g. websites of local, regional and national stroke patients' associations, the rehabilitation knowledge network, quality network rehabilitation, professional associations of physical therapy, occupational therapy and speech therapy. Third, the internet and the social media were searched for messages and as well as reports from relevant care networks (search terms (in Dutch) 'network', 'organization', 'healthcare', 'definition', 'integrated care' and 'interprofessional').And fourth, during the research, presentations were held at various symposia, after which networks could register to participate in the study.

\section{Questionnaire Network Coordinators}

By means of an online questionnaire among the coordinators of the identified stroke networks, followed by a telephone interview if data were unclear or incomplete, the characteristics of the networks were recorded. The questions concerned the following: the number of professionals and their background (physical therapists, occupational therapists, psychologists, speech therapists, nurses, social workers, dietitians, general practitioners), quality of care (treatment goals set, goals evaluated and reset, exchange of patient data, shared patient record, combined treatment program, case management, requirements for membership yes/no), requirements (education, minimum number of stroke patients treated, registration in quality register of professional body), objectives of the network (improve quality of care, implement guidelines, offer specific expertise, improvecommunication, improve coordination, share knowledge and information, improve organizational aspects of care, improve efficiency of care, offer care in local community, care, uniform treatment protocols, prevent under treatment, visibility) and future perspectives (need for uniformity, need for certification, need for nationwide support of content and organization of networks). Two open questions about success factors and barriers were added: What is in your opinion the reason for success of this network? What barriers are relevant in your opinion regarding this network?

\section{Questionnaire Network Members}

The network coordinators were asked to invite the network members to fill in an online survey based on questionnaires used to describe the organization and outcomes of primary care networks for other chronic conditions (Fyranet network; Parkinson Net network) $[15,22]$.

The survey for members comprised questions regarding: profession, tasks and responsibilities in the network, costs and revenues being a member, requirements to become and stay a member of the network, number of years working as a professional and specifically regarding stroke patients, postgraduate courses or congresses, use of guidelines for stroke, use of a uniform treatment protocol within the network, outcome measures (patient level and aggregated at group level), the use of outcomes to adapt treatment program, the role of a case manager, way of communication between members concerning patients, familiarity with expertise of colleague members, procedures to refer patients to other members, contacts with professionals outside the network, contacts with general practitioner or hospital organizations, organization of network meetings, attendance of network meetings, participation in InterVision, number of stroke patient treated last year, number of patients referred to other members and to professionals outside the network, audits being organized, satisfaction (with the network; the network meetings; the number of referred patients; the publicity of the network for patients, colleagues and referrers; the communication between network members), the need for uniformity in stroke networks, the need for nationwide or centralized support for networks, expectations over 5 years, the need for support to be successful as a network member. The following questions about success factors and barriers were added: What is in your opinion the reason 
Citation: Arwert HJ, Borcherts JHR, Vree FMv, Groeneveld IF, Meesters JJ, et al. (2019) Recommendations for Stroke Networks in Primary Care. J Phys Med Rehabil Disabil 5: 039.

- Page 3 of 7 •

for success of this network? What barriers are relevant in your opinion regarding this network?

\section{Invitational Conference}

In order to formulate recommendations based on the results of the inventory, an invitational conference with stakeholders was organized: local scientific advisory board of patients, PCSN health providers, stroke network coordinators, national patients' associations, national professionals' associations (physical therapists, physical medicine and rehabilitation, neurology, general practitioner), national stroke knowledge network (CVA Kennisnetwerk), health insurance companies, The Netherlands organization for health research and development (ZonMW; Zorg Onderzoek Nederland Medische Wetenschappen) and the quality fund for medical specialists (SKMS; stichting Kwaliteitsgelden Medisch Specialismen). Subsequently, the following topics were discussed in smaller groups: the requirements regarding quality of the networks and individual members, communication and cooperation, finance, and standardization.

\section{Results}

\section{PCSN: network coordinators' perception}

Fifteen stroke networks met the definition. Their geographical distribution over the Netherlands is shown in Figure 1. All 15 coordinators of these networks were willing to collaborate and completed the online survey. In 5 cases additional contact by telephone was necessary. The median number of members per network was 27 , range 4-140. Table 1 presents the professional background of network members and organizational aspects. Three networks had been instituted in the last two years; of the other 12 networks 6 had been instituted before 2010. Three networks did not only focus on stroke but on neurological disorders in a broader sense. Three networks were monodisciplinary, physical therapists only.

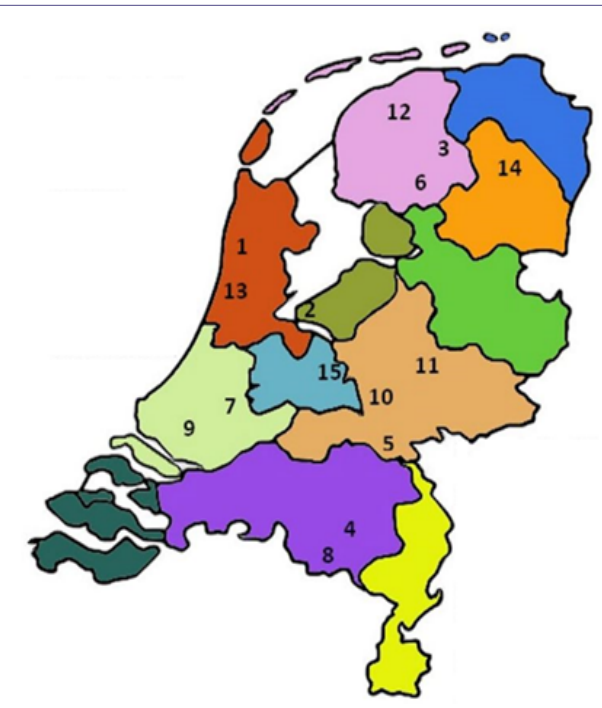

Figure 1: Geographical distribution of fifteen stroke networks that were identified in the Netherlands.

1 Alkmaar; 2 Almere; 3 Drachten; 4 Eindhoven; 5 Nijmegen; 6 Heereveen; 7 Mid-Holland; 8 Brabant S-E; 9 Rotterdam; 10 Ede; 11 Apeldoorn; 12 Leeuwarden; 13 Mid-Kennemerland; 14 Assen; 15 Eemland.

\begin{tabular}{|c|c|}
\hline Representation of professions: & Number of Networks \\
\hline Physical therapists & 15 \\
\hline Occupational therapists & 12 \\
\hline Psychologists & 11 \\
\hline Speech therapists & 8 \\
\hline Nurse & 7 \\
\hline Social workers & 5 \\
\hline Dietitians & 5 \\
\hline GP & 5 \\
\hline \multicolumn{2}{|l|}{ Quality aspects: } \\
\hline Goals set & 13 \\
\hline Goals evaluated and reset & 13 \\
\hline Exchange of patient data & 12 \\
\hline Combined treatment program & 9 \\
\hline Case management & 6 \\
\hline Shared patient record & 1 \\
\hline $\begin{array}{l}\text { Requirements for membership yes/no } \\
\text { If available, requirements concerned: }\end{array}$ & $14 / 1$ \\
\hline - Education & $12 / 14$ \\
\hline - Minimum number of stroke patients treated & $11 / 14$ \\
\hline - Registration in quality register of professional body & $6 / 14$ \\
\hline
\end{tabular}

PCSN: primary care stroke network; GP: general practitioner.

Table 1: Health professionals, quality of care aspects, and requirements for membership in primary care networks, and the number of networks in which these (professionals, aspects and requirements) are represented.

Requirements for membership were imposed on network members in 14 networks. These could concern requirements for admission to the network and/or for continuation of membership. The extent to which admission and continuation requirements were set, operationalized and described varied among networks. In the 11 networks that had set requirements for a minimum number of stroke patients, the minimum number varied from 5 to 14 patients per year.

Concerning the required registrations in professional bodies, coordinators referred to the guidelines and quality registers of the professional groups. Educational requirements for network memberswere found to differ among professional groups, with reference to the professional group's guideline and to various training courses in the field of stroke.

Some of the network coordinators appointed additional requirements, such as signing a covenant, financial contribution, 'interest, motivation and passion', willingness to collaborate and location of the practice. For continuation of the membership, apart from the aforementioned requirements, the presence at network meetings and/ or reference evenings was also required by various networks.All 15 networks had formulated objectives, including quality, coordination, efficiency and publicity (Table 2). Regarding quality of care, aspects that were mentioned concerned the application of national frameworks and guidelines, the provision of high-quality, evidence-based care, to enhance the skills of professionals and the coordination in the chain of care of the organizations involved. For this purpose, they focused on sharing knowledge, education and expertise promotion and some perform structured InterVision. From the networks' perspective, the needs of the individual patient should be leading in stroke care. 
Citation: Arwert HJ, Borcherts JHR, Vree FMv, Groeneveld IF, Meesters JJ, et al. (2019) Recommendations for Stroke Networks in Primary Care. J Phys Med Rehabil Disabil 5: 039.

- Page 4 of 7 •

\begin{tabular}{|l|l|}
\hline Improve quality of care & 7 \\
\hline Implement guidelines & 5 \\
\hline Offer specific expertise & 6 \\
\hline Improve communication & 5 \\
\hline Improve coordination & 5 \\
\hline Share knowledge and information & 4 \\
\hline Improve organizational aspects of care & 4 \\
\hline Improve efficiency of care & 3 \\
\hline Offer care in local community & 3 \\
\hline Care & 2 \\
\hline Uniform treatment protocols & 2 \\
\hline Prevent undertreatment & 2 \\
\hline Visibility/publicity & 1 \\
\hline
\end{tabular}

Table 2: Objectives of PCSN (Primary Care Stroke Networks) as reported by the network coordinators $(\mathrm{n}=15)$.

Six networks had a formalized structure and formed an association or partnership. Two of these networks had a statute and/or regulations. In the other networks, the cooperation structure was less formally established but based on agreements, shaped by informal coordinators or by periodic consultation between the members. Tasks and responsibilities of the network members were described in 8 networks.

The networks were funded in various ways, according to the coordinators' answers. Eight networks were (partly) financed by a contribution from the network members, 5 networks received funds from affiliated centers, hospitals or intramural partners, 1 network received financial support by a health insurer and 1 network indicated that they were not being financed at all.

All coordinators indicated that network meetings were organized. For most of the networks, quality aspects had been elaborated, such as the exchange of patient data, a shared treatment protocol and uniform measurements of the treatment outcomes.

Regarding barriers and facilitators for the continuation of the networks, the coordinators often mentioned a lack of time and money as the most important impeding factors. Furthermore, achieving a minimum number of treatment patients was not always guaranteed. The 'short communication lines' and interprofessional contacts were mentioned as an important facilitating factor. Network members experienced trust, involvement and know each other personally. In addition, the 'bottom-up' formation and organization of the networks was mentioned as a success factor.

\section{Structure and process of PCSN: network members}

Table 3 shows the characteristics of the 139 responding network members (response $25.5 \%$ ). Most of the respondents $(83 \%$ ) worked in the field of stroke patients more than 5 years. Almost half of them had participated in stroke-oriented postgraduate courses or training one or more times during the past year and almost all network members participated in network meetings in the past year.

Network members used the following facilities to communicate about their patients: e-mail (48\%), personal contact (45\%), telephone (44\%), via team meetings (32\%) or in writing $(24 \%)$. To a much lesser extent, communication took place by fax $(6 \%)$ or a joint electronic patient file (4\%).

\begin{tabular}{|l|c|l|}
\hline Experience and education & $\mathrm{N}$ & $\%$ \\
\hline Took part in $\geq 1$ network meeting last year & $87 / 97$ & $90 \%$ \\
\hline Treats stroke patients $>5$ years & $102 / 123$ & $83 \%$ \\
\hline$>5$ stroke patients last year & $71 / 91$ & $78 \%$ \\
\hline Followed symposium or congress on stroke $<5$ yrs & $89 / 125$ & $71 \%$ \\
\hline Follows education on stroke $>1$ per year & $60 / 126$ & $48 \%$ \\
\hline Intervision in network & $37 / 101$ & $37 \%$ \\
\hline Quality of care & $100 / 125$ & $80 \%$ \\
\hline Following guidelines for stroke & $55 / 106$ & $52 \%$ \\
\hline Evaluations of goals during treatment & $52 / 108$ & $48 \%$ \\
\hline Structured outcome measurements & $42 / 122$ & $34 \%$ \\
\hline Using uniform treatment protocol & $23 / 81$ & $28 \%$ \\
\hline Adjustment of goals during treatment & $22 / 108$ & $20 \%$ \\
\hline Being case manager for stroke patient & \multicolumn{2}{|l|}{} \\
\hline
\end{tabular}

Table 3: Results from a survey among members of 15 PCSN ( $=139$; answer categories Yes or No).

In general, network members were satisfied with the number and content of network meetings. Almost half of the responding network members were satisfied with the communication within the network, a similar proportion experienced an improvement in quality of care since being part of the stroke network (46\%). Two thirds of the network members were unsatisfied with the publicity of the stroke network among colleagues, general practitioners, referring institutions and patients.

The available (inter)national profession-specific guidelines were followed by most practitioners, however, guidelines were not available for every discipline. Just over a third of the responding network members reported to have an interdisciplinary treatment program, about half of them measured progress and outcomes of the treatment of stroke.

Network members mentioned a lack of time and the lack of compensation for network activities as barriers. The volume requirements were in some cases difficult to meet. Few members also mentioned the risk of competition for production as an impeding issue. The above mentioned 'short lines' were considered as a facilitator. Knowing each other's skills and learning from each other was enhanced by working in networks, specifically in networks with less members.

A formal instrument for certification of quality is required according to $41 \%$ of the responding network members. Approximately $60 \%$ of network members saw a central or national financial support as a prerequisite to stimulate standardization in the content and organization of the stroke networks. A small proportion of respondents, ranging from $6 \%$ to $17 \%$, believed that more uniformity, central support or quality certification was not required.

\section{Recommendations for Future Development: Invitational Conference}

The participants $(n=43)$ in the invitational conference were representing local scientific advisory board of patients, PCSN health providers, stroke network coordinators, national patients' associations, national professionals' associations (physical therapists, physical medicine and rehabilitation, neurology, general practitioner), national stroke knowledge network (CVA Kennisnetwerk), health insurance 
Citation: Arwert HJ, Borcherts JHR, Vree FMv, Groeneveld IF, Meesters JJ, et al. (2019) Recommendations for Stroke Networks in Primary Care. J Phys Med Rehabil Disabil 5: 039.

companies, the Netherlands organization for health research and development (ZonMW) and the quality fund for medical specialists (SKMS).

The results of the conference, in terms of recommendations, are summarized in Table 4. The participants agreed upon a multidisciplinary network being preferred over a monodisciplinarynetwork. Network meetings were important in meeting other members and for sharing knowledge. Responsibility for the organization and activities of the network must be assigned to a network coordinator. A shared vision on treatment and outcome measures promotes the quality of care.

Minimal requirements for admission and continuation as a PCSN member should comprise postgraduate education, minimal years of experience with and volume of stroke patients, registration in quality registries if applicable, participation in network meetings and InterVision.

\begin{tabular}{l}
\hline Structure \\
\hline $\begin{array}{l}\text { Formulate a shared vision on the treatment of stroke patients, based on existing guide- } \\
\text { lines, and a collaborative approach regarding measurable, concrete goals. }\end{array}$ \\
\hline $\begin{array}{l}\text { Develop a multidisciplinary network: physical therapy, occupational therapy, speech } \\
\text { therapy, supplemented when available with disciplines such as psychology, dietetics } \\
\text { and nursing }\end{array}$ \\
\hline $\begin{array}{l}\text { Involve Other stakeholders in the network: GP, hospital organizations, rehabilitation } \\
\text { facilities and (regional) patient associations }\end{array}$ \\
\hline Tasks and responsibilities of network members must be formulated \\
\hline $\begin{array}{l}\text { Consider a broader target group with similar neurological problems, for example 'pa- } \\
\text { tients with non-progressive central neurological disorders' or 'patients with acquired } \\
\text { brain disorders' }\end{array}$ \\
\hline $\begin{array}{l}\text { Organize network meetings at least once a year to ensure the coherence within a net- } \\
\text { work and the quality of the care provided. }\end{array}$ \\
\hline Ensure funding for network coordination \\
\hline $\begin{array}{l}\text { Set up a quality system for the treatment of stroke patients in which performance } \\
\text { indicators can be recorded }\end{array}$ \\
\hline Consider a legal status for the network \\
\hline Process \\
\hline $\begin{array}{l}\text { Establish agreements with referring institutions about content and timing of infor- } \\
\text { mation transfer }\end{array}$ \\
\hline Make arrangements on internal and external lines of communication of the PCSN \\
\hline Formulate requirements for entry and continuation of membership \\
\hline Ensure publicity and visibility of the PCSN \\
formulated at an invitational conference. \\
GP: general practitioner; PCSN: primary care stroke network \\
\hline
\end{tabular}

Agreements with referring institutions about content and moment of information transfer should be established to improve the continuity of care for stroke patients. Other primary care providers such as GP's (general practitioners) and community nurses and should also be involved in the networks. Furthermore, effective publicity and accessibility were considered important for the success of the PCSN.

Members contributed financially to the network, but additional funding is needed for both the start and continuation of the network. Participants argued for a central, national support for stroke networks to promote uniformity in the organization of the networks. This central support should facilitate the development of regional networks and their visibility for referrers as well as for patients, formulation of requirements for education and quality management, and exchange of knowledge within networks. Participants also argued for a national certification.

\section{Discussion}

With a considerable proportion of patients having some limitations in functioning after initial hospitalization and/or inpatient or outpatient rehabilitation for stroke, there is a need for anadequate continuation of care in the community setting. Networks of primary care professionals may enhance the quality and accessibility of care but research in this area is scanty. This study identified 15 primary care networks in the Netherlands, with a large variety in their structure and processes. Time and money were most frequently mentioned as barriers for continuation, whereas mutual trust, commitment and direct lines of communication were mentioned as success factors. During an invitational conference, a set of recommendations for the future organization and development of PCSN was formulated; the need for a national, centralized approach being a consistent advice.

In most countries some form of network organization regarding the care for stroke patients is pursued. The structure and objectives of these networks may differ. In the Canadian stroke network best practices were advocated in the acute, subacute and chronic stroke care and a central registry was developed to collect necessary information on stroke risk factors, symptoms, treatment and hospital management to inform research and to identify gaps in care (http://canadianstrokenetwork.ca/en/). The KompetenznetzSchlaganfall (qualified stroke network) in Germany is primarily focused on research efforts and implementation of its results (http://www.kompetenznetz-schlaganfall. de/89.0.html). The NHS in the United Kingdom established in 2013 the strategic clinical networks that serve in key areas of major health and wellbeing challenges such as stroke. Each of the five NHS region teams may develop other strategic clinical networks depending on local need. As an example, the south east coast strategic clinical networks issued the 'Life After Stroke Commissioning Guidance'. The empowerment of stroke survivors and their carers to manage their care, with the help of appropriately skilled staff, is a key theme of this guidance, offering evidence-based guidelines on care for stroke survivors (https://www.england.nhs.uk/south/wp-content/uploads/ sites/6/2017/07/life-after-stroke.pdf).

The evidence for the effectiveness of primary care networks is gradually growing. Enhanced expertise and coordination of teams in a variety of patient groups showed a limited effect on patientoutcomes [9]. In a Cochrane study the impact of practice-based interventions designed to improve interprofessional collaboration amongst health and social care professionals was compared to usual care or to an alternative intervention. Strategies to improve interprofessional collaboration between health and social care professionals may slightly improve patient functional status, professionals' adherence to recommended practices, and the use of healthcare resources [11]. Further research is indicated to understand the efficacy of PCSN in stroke populations.

Our results indicate that sufficient financial resources are essential to keep an interprofessional stroke network running. These may consist of a contribution from members, possibly supplemented with funding from other parties (municipality, hospitals, and health insurance). The quality of the network can be improved by setting up a quality system for the treatment of stroke patients in which outcomes are recorded to and used to adapt the treatment protocol. 
Citation: Arwert HJ, Borcherts JHR, Vree FMv, Groeneveld IF, Meesters JJ, et al. (2019) Recommendations for Stroke Networks in Primary Care. J Phys Med Rehabil Disabil 5: 039.

Process aspects should focus on collaboration, quality of care and visibility of the network. Agreements with referring physicians on sharing information and on shared opinions about treatment protocol is important. Sharing information from patients within the network must be done with due regard to the laws and regulations on privacy. Outcome measures at the level of the individual patient, care provider and the network need to be established. The network should be brought to the attention of local and regional health institutions and practices (hospitals, rehabilitation facilities, nursing homes, general practitioners and community nurses).

This study has some limitations. Possibly, not all primary care stroke networks were found that met the criteria, although extensive efforts have been made to identify all stroke networks in the Netherlands. Only a minority of network members did respond to the invitation of the questionnaire. Strengths of this study are the fact that all coordinators of the included networks did participate, and that a set of recommendations for further development of PCSN was discussed and formulated at an invitational conference with relevant stakeholder.

\section{Conclusion}

In conclusion, there is no uniformity regarding the structure and process among 15 regional PCSN in the Netherlands. Recommendations are proposed for the organization of PCSN, based on structured response from network coordinators, network members and stakeholders. Centralized coordination and support is advocated. Further research is necessary to establish the beneficial effects of coordinated interprofessional care for stroke patients in primary care networks.

\section{Publication Standards}

All authors accept the publication standards of Herald Scholarly Open Access.

\section{Declaration of Interest}

All authors state that there are no declarations of interest.

This work was supported by SKMS (Quality Fund for Medical Specialists in the Netherlands; project number 38258073).

\section{References}

1. RIVM(2019) National Institute for Public Health and Environment.

2. Van Dis I, Buddeke J, Vaartjes I, Visseren FLJ, Bots ML (2015) Hart- envaatziekten in Nederland 2015.

3. Benjamin EJ, Blaha MJ, Chiuve SE, Cushman M, Das SR, et al. (2017) Heart Disease and Stroke Statistics-2017 Update: A Report From the American Heart Association. Circulation 7: 135.

4. National Stroke Guideline (2019) Kv K Federatie Medisch Specialisten, Netherlands.

5. Taule T, Strand LI, Skouen JS, Råheim M (2015) Striving for a life worth living: stroke survivors' experiences of home rehabilitation. Scand J Caring Sci 29: 651-661.
6. Groeneveld IF, Arwert HJ, Goossens PH, Vliet Vlieland TPM (2018) The Longer-term Unmet Needs after Stroke Questionnaire: Cross-Cultural Adaptation, Reliability, and Concurrent Validity in a Dutch Population. J Stroke Cerebrovasc Dis 27: 267-275.

7. LoTS care LUNS study team (2013) Validation of the longer-term unmet needs after stroke (LUNS) monitoring tool: a multicentre study. ClinRehabil 27(11): 1020-1028.

8. Clark ML, Gropen T (2015) Advances in the stroke system of care. Curr Treat Options Cardiovasc Med 17: 355.

9. Bosch M, Faber MJ, Cruijsberg J, Voerman GE, Leatherman S, et al. (2009) Review article: Effectiveness of patient care teams and the role of clinical expertise and coordination: a literature review. Med Care Res Rev 66: 5-35.

10. De Stampa M, Vedel I, Bergman H, Novella JL, Lapointe L (2009) Fostering participation of general practitioners in integrated health services networks: incentives, barriers, and guidelines. BMC Health ServRes 17: 9-48.

11. Reeves S, Pelone F, Harrison R, Goldman J, Zwarenstein M (2017) Interprofessional collaboration to improve professional practice and healthcare outcomes. Cochrane Database Syst Rev 22: 6.

12. Allison R, Shelling L, Dennett R, Ayers T, Evans PH, et al. (2011) The effectiveness of various models of primary care-based follow-up after stroke: a systematic review. Prim Health Care Res Dev 12: 214-222.

13. Forster A, Young J, Chapman K, Nixon J, Patel A, et al. (2015) Cluster Randomized Controlled Trial: Clinical and Cost-Effectiveness of a System of Longer-Term Stroke Care. Stroke 46: 2212-2219.

14. Pindus DM, Mullis R, Lim L, Wellwood I, Rundell AV, et al. (2018) Stroke survivors' and informal caregivers' experiences of primary care and community healthcare services - A systematic review and meta-ethnography. PLoS One 21: 13.

15. Verhoef J, Oosterveld FG, Hoekman R, Munneke M, Boonman DC, et al. (2004) A system of networks and continuing education for physical therapists in rheumatology: a feasibility study. Int J Integr Care 4: 19.

16. Klokkerud M, Hagen KB, Kjeken I, Bremander A, Hørslev-Petersen K, et al. (2012) Development of a framework identifying domains and elements of importance for arthritis rehabilitation. J Rehabil Med 44: 406-413.

17. Van der Marck MA, Bloem BR, Borm GF, Overeem S, Munneke M, et al. (2013) Effectiveness of multidisciplinary care for Parkinson's disease: a randomized, controlled trial. MovDisord 28: 605-611.

18. Hageman D, van den Houten MM, Spruijt S, Gommans LN, Scheltinga MR, et al. (2017) Supervised exercise therapy: it does work, but how to set up a program? J CardiovascSurg (Torino) 58: 305-312.

19. Ypinga JHL, de Vries NM, Boonen LHHM, Koolman X, Munneke M, et al. (2018) Effectiveness and costs of specialised physiotherapy given via ParkinsonNet: a retrospective analysis of medical claims data. Lancet Neurol 17: 153-161.

20. Donabedian A (1966) Evaluating the quality of medical care. Milbank Mem Fund Q 44: 166-206.

21. Ayanian JZ, Markel H (2016) Donabedian's Lasting Framework for Health Care Quality. N Engl J Med 375: 205-207.

22. Wensing M, van der Eijk M, Koetsenruijter J, Bloem B, Munneke M, et al. (2011) Connectedness of healthcare professionals involved in the treatment of patients with Parkinson's disease: a social networks study. Implement Sci 6: 67. 


\section{Hit}

Journal of Anesthesia \& Clinical Care

Journal of Addiction \& Addictive Disorders

Advances in Microbiology Research

Advances in Industrial Biotechnology

Journal of Agronomy \& Agricultural Science

Journal of AIDS Clinical Research \& STDs

Journal of Alcoholism, Drug Abuse \& Substance Dependence

Journal of Allergy Disorders \& Therapy

Journal of Alternative, Complementary \& Integrative Medicine

Journal of Alzheimer's \& Neurodegenerative Diseases

Journal of Angiology \& Vascular Surgery

Journal of Animal Research \& Veterinary Science

Archives of Zoological Studies

Archives of Urology

Journal of Atmospheric \& Earth-Sciences

Journal of Aquaculture \& Fisheries

Journal of Biotech Research \& Biochemistry

Journal of Brain \& Neuroscience Research

Journal of Cancer Biology \& Treatment

Journal of Cardiology: Study \& Research

Journal of Cell Biology \& Cell Metabolism

Journal of Clinical Dermatology \& Therapy

Journal of Clinical Immunology \& Immunotherapy

Journal of Clinical Studies \& Medical Case Reports

Journal of Community Medicine \& Public Health Care

Current Trends: Medical \& Biological Engineering

Journal of Cytology \& Tissue Biology

Journal of Dentistry: Oral Health \& Cosmesis

Journal of Diabetes \& Metabolic Disorders

Journal of Dairy Research \& Technology

Journal of Emergency Medicine Trauma \& Surgical Care

Journal of Environmental Science: Current Research

Journal of Food Science \& Nutrition

Journal of Forensic, Legal \& Investigative Sciences

Journal of Gastroenterology \& Hepatology Research

Journal of Gerontology \& Geriatric Medicine
Journal of Genetics \& Genomic Sciences

Journal of Hematology, Blood Transfusion \& Disorders

Journal of Human Endocrinology

Journal of Hospice \& Palliative Medical Care

Journal of Internal Medicine \& Primary Healthcare

Journal of Infectious \& Non Infectious Diseases

Journal of Light \& Laser: Current Trends

Journal of Modern Chemical Sciences

Journal of Medicine: Study \& Research

Journal of Nanotechnology: Nanomedicine \& Nanobiotechnology

Journal of Neonatology \& Clinical Pediatrics

Journal of Nephrology \& Renal Therapy

Journal of Non Invasive Vascular Investigation

Journal of Nuclear Medicine, Radiology \& Radiation Therapy

Journal of Obesity \& Weight Loss

Journal of Orthopedic Research \& Physiotherapy

Journal of Otolaryngology, Head \& Neck Surgery

Journal of Protein Research \& Bioinformatics

Journal of Pathology Clinical \& Medical Research

Journal of Pharmacology, Pharmaceutics \& Pharmacovigilance

Journal of Physical Medicine, Rehabilitation \& Disabilities

Journal of Plant Science: Current Research

Journal of Psychiatry, Depression \& Anxiety

Journal of Pulmonary Medicine \& Respiratory Research

Journal of Practical \& Professional Nursing

Journal of Reproductive Medicine, Gynaecology \& Obstetrics

Journal of Stem Cells Research, Development \& Therapy

Journal of Surgery: Current Trends \& Innovations

Journal of Toxicology: Current Research

Journal of Translational Science and Research

Trends in Anatomy \& Physiology

Journal of Vaccines Research \& Vaccination

Journal of Virology \& Antivirals

Archives of Surgery and Surgical Education

Sports Medicine and Injury Care Journal

International Journal of Case Reports and Therapeutic Studies

Journal of Ecology Research and Conservation Biology

Submit Your Manuscript: http://www.heraldopenaccess.us/Online-Submission.php 